\title{
Towards assessing fine-scale indicators for the spatial transmission risk of Fasciola bepatica in cattle
}

\author{
Johannes Charlier ${ }^{1}$, Sita Carolien Bennema ${ }^{1}$, Yannick Caron ${ }^{2}$, Michel Counotte ${ }^{1}$, \\ Els Ducheyne ${ }^{3}$, Guy Hendrickx³ ${ }^{3}$ Jozef Vercruysse ${ }^{1}$ \\ ${ }^{1}$ Department of Virology, Parasitology and Immunology, Faculty of Veterinary Medicine, Ghent University, \\ 3820 Merelbeke, Belgium; 'Department of Infectious and Parasitic Diseases, Faculty of Veterinary Medicine, \\ University of Liège, 4000 Liège, Belgium; ${ }^{3}$ Avia-GIS, Risschotlei 33, 2980 Zoersel, Belgium
}

\begin{abstract}
In order to improve the spatial resolution of current risk maps for fasciolosis in cattle, more knowledge is needed with respect to farm-level factors that determine infection risk. In this study, we visited 39 dairy farms within a predefined low- and high-risk area for fasciolosis in Belgium and assessed their infection status by an indirect bulk tank milk enzyme-linked immunosorbent assay (ELISA). Management factors were collected and all pastured lands of the farms were visited to identify and georeference potential snail habitats. The habitats were visually characterised, investigated for the presence of the intermediate host snails of Fasciola hepatica (i.e.Galba truncatula and Radix spp.) and used in a geographical information system (GIS) to construct overlays including information on soil and hydrology. A linear regression model was used to evaluate associations between bulk tank milk ELISA results and farm level management and habitat factors. A logistic, mixed model was used to identify possible risk factors for the presence of intermediate host snails on a potential habitat. Potential snail habitats were found in 35 out of 39 farms. A total of 87 potential habitats were identified and on $29 \%$ of these, intermediate host snails were found. The number of potential habitats, the presence of snails, drainage of pastures, month of turnout of the cows, stocking rate, type of watering place and risk area were significantly associated with the bulk tank milk ELISA result and explained $85 \%$ of the observed variation. Intermediate host snails were more likely to be present with increasing surface of the potential habitat and on loamy soils. This study confirms the importance of farm management factors in the infection risk for $F$. hepatica in cattle and highlights that the combination of management factors with characterization of snail habitats is a powerful means to predict the infection risk with $F$. hepatica at the individual farm level. Further research is needed to investigate how this knowledge can be incorporated in nation-wide spatial distribution models of the parasite.
\end{abstract}

Keywords: fasciolosis, Fasciola hepatica, Galba truncatula, cattle, epidemiology, geographical information system, Belgium.

\section{Introduction}

The liver fluke Fasciola hepatica is a trematode parasite with an economic impact on livestock production worldwide. In northern Belgium (Flanders), the yearly cost of infections with this parasite in dairy cattle has been estimated at $€ 8.2$ million or $€ 30$ per adult dairy cow present in the population (Charlier et al., 2007, 2009). Because of the dependence on climatic and environmental conditions of both the intermediate hosts and the free-living stages of F. hepatica, there is an important spatial component in the epidemiology of the disease and spatial distribution models have been developed for several regions across the world (Malone and Zukowski, 1992; Yilma and Malone,

Corresponding author:

Johannes Charlier

Department of Virology, Parasitology and Immunology

Faculty of Veterinary Medicine, Ghent University

Salisburylaan 133, 9820 Merelbeke, Belgium

Tel. + 329264 7400; Fax: +3292647496

E-mail: johannes.charlier@ugent.be
1998; Cringoli et al., 2002; Tum et al., 2004; Durr et al., 2005; Fuentes, 2006; Rapsch et al., 2008; Dutra et al., 2010; McCann et al., 2010; Bennema et al., 2011).

Generally, validation of these models with field observations has shown that they are capable of identifying regions at high risk for $F$. hepatica presence, and hence may act as a means to increase awareness of the disease among animal health workers and farmers. However, thus far, in most studies, the risk areas comprise large regions (e.g. study of McCann et al., 2010 where the risk has been estimated per postcode area with a mean surface of $2,000 \mathrm{~km}^{2}$ ) and it is known that, both within low or high risk areas, F. hepaticainfected and uninfected farms can co-exist next to each other, depending on the presence/absence of suitable habitats for the principal intermediate host Galba truncatula and local farm management practices (Bennema et al., 2009). Therefore, to improve the usefulness of risk maps for fasciolosis, we ought to define the risk for infection on a finer scale, with the ultimate aim of providing farm-specific risk. The first attempt, to our knowledge, to address this issue was made by 
Zukowski et al. (1991, 1993), who combined habitat mapping, soil characteristics and animal stocking rate using a geographical information system (GIS) to estimate the disease risk at the farm level in the southern part of the United States of America. Since then, however, no further progress has been achieved in this field.

The aim of this study was to explore the combined use of habitat characterization with pasture management factors to explain differing levels of exposure to F. hepatica of farms within a common risk area for fasciolosis in Belgium.

\section{Materials and methods}

Farm selection and collection of management information

Significant clustering, based on bulk tank milk enzyme-linked immunosorbent assay (ELISA) results, has been observed in the levels of exposure to F. hepatica in dairy farms in Flanders, Belgium (Bennema et al., 2009). A cluster with high and another one with low seroprevalence of $F$. hepatica were selected for this study and the locations from where they came were defined as a high and low risk area, respectively. Within each risk area, the farms were randomised, stratified by bulk tank milk $F$. hepatica ELISA result. The farm owners were contacted by phone until in each area 20 farms had been found that would participate in the study. In the high risk area, however, only 19 farms could be visited, resulting in a total of 39 farms in the study.

The farms were visited between 10 September and 31 October, 2008. During the visit, information was collected through a questionnaire asking for herd size (number of adult dairy cows), farm type (dairy only versus dairy and beef), average milk production per year, pasture management practices (i.e. amount of access to pasture, grazing time per day, month of turnout on pasture, month of stabling, grazing together of dry cows with replacement animals, average number of cows grazing per ha on a parcel, whether pastures were mowed, kind of watering place, drainage of pastures, spreading manure on pasture, use of molluscicides on pasture) and treatment with anthelminthics. In case a question could not be answered by the farmer or was not applicable, it was left blank. In addition, the farmer was asked to locate all his/her pastured land on the ground plan of his/her property for subsequent inspection.
Identification and characterization of possible snail habitats

All pastured lands were visited and potential snail habitats were georeferenced. A possible snail habitat was defined as a visible humid area on the pasture that could be (i) humid on the time of the visit or (ii) considered to remain humid during prolonged periods based on the location and vegetation. Additional registered information included size $\left(<10 \mathrm{~m}^{2}, 10-20 \mathrm{~m}^{2}\right.$, $>20 \mathrm{~m}^{2}$ ), type of habitat (diffuse humid area or border of drainage ditch, pool or water trough) and whether it was located on a pasture for adult cows or heifers.

\section{Snail collection and determination of infection status with F. hepatica}

Thirty minutes were spent at potential habitats to search for snails and to collect them. The snail genus was determined in the laboratory based on size and morphology of the shell according to Frömming (1956) and Nisters (1999). Only snails identified as G. truncatula or Radix spp. were considered and counted as they were the only potential intermediate host snails for F. hepatica in the area. G. truncatula is the main intermediate host of $F$. hepatica in Europe, but Radix spp. may act as incidental intermediate hosts (Caron et al., 2007; Relf et al., 2009). The presence of Fasciola spp. DNA in the collected snails was assessed by polimerase chain reaction (PCR) amplification of a 124 bp Fasciola spp.-specific probe as previously described by Kaplan et al. (1995) and Caron et al. (2007). The sensitivity and specificity of this technique have been estimated at $99 \%$ and $100 \%$, respectively (Kaplan et al., 1995).

\section{Construction of a GIS}

The potential habitats were overlayed onto a GIS soil map of Flanders (OC GIS Vlaanderen, Belgium) and a Flemish hydrological map (OC GIS Vlaanderen, Belgium). The soil texture and drainage classification of the habitats were deducted from the former map, while the latter made it possible to calculate the distance to the nearest water body with a precision of 50 $\mathrm{m}$. The Belgian drainage classification system (Van Ranst and Sys, 2000) contains nine classes of natural drainage: a-b signifying (very) dry soils, $c-d$ signifying moderately dry/humid soils and e-i, which are increasingly humid soils. The bulk-tank milk $F$. hepatica ELISA results, presence of snails overall, as well as presence of $F$. hepatica-infected snails, were included 
in additional layers. GIS was constructed in Manifold System 7x Professional Edition and the habitats were plotted on a ecological map created for this purpose.

\section{Statistical analysis}

Two analyses were conducted to investigate the associations of management and habitat factors with (i) the bulk tank milk ELISA result of the farm (model 1); and (ii) the presence of an intermediate host on the farm (model 2). Model 1 was based on multivariable linear regression with a backward stepwise selection procedure (variables were retained only when their significance level was $<0.05)$. The bulk tank milk ELISA result was the dependent variable and farm level variables concerning management or potential snail habitats were evaluated as independent variables. Because samplings were done in two distinct geographical zones (risk areas), observations within each zone could not be assumed to be independent from each other. Therefore, "risk area" was included to correct for possible bias introduced by the selection procedure. Once significant main effects were identified, all possible 2-way interactions were evaluated. Heteroscedasticity was evaluated by Levene's test for homogeneity of variances and a plot of the standardised residuals versus predicted values. Model 2 was based on a logistic mixed model where the presence of the intermediate host (yes/no) was the outcome variable and habitat factors were evaluated as fixed factors. Because more than one potential habitat was present for most farms, it was defined as a random effect. Only variables that were univariately associated with the outcome variable at a significance level of $a=$ 0.20 were considered for inclusion in the multivariate model. The variable soil type was re-categorized from the Belgian classification system (Van Ranst and Sys, $2000)$ into a 2-category variable: "loam", i.e. classification "A" according to the Belgian classification system) versus "no loam" that includes all other soil types. Model 1 was conducted in SPSS 16.0 (SPSS Inc.; 2008; www.spss.com), and model 2 was conducted in MLwiN 2.19 (Centre for Multilevel Modelling, University of Bristol; www.cmm.bristol.ac.uk/MLwiN).

\section{Results}

\section{Factors related to farm management}

The average [minimum, maximum] response per question in the questionnaire was $95 \%[69 \%, 100 \%]$. The average [minimum, maximum] herd size was 33 $[14,65]$ adult dairy cows. In all farms, cows and heifers had access to pasture, except for one farm where the cows were kept in the stable all year round. The grazing season typically started in April $176 \%$ of farms) and ended in October or November $(47 \%$ in each month). Dry cows grazed on the pastures of replacement stock in $41 \%$ of the farms. Stocking rate (number of cows per ha on a parcel) was $<5,5-10$ or $>10$ on $54 \%, 40 \%$ and $6 \%$ of the farms, respectively. Cow pastures were completely or partially mowed by $66 \%$ of the farms. All types of watering were used, but most applied a pump $(45 \%)$ or an open tub $(40 \%)$. The pastures were completely or partially drained for $16 \%$ and $32 \%$ of the farms, respectively. In most of the farms $(70 \%)$ pools or brooks were not fenced off and could be reached by the animals. Molluscicides (calcium cyanamide) or regular flukicide treatment were applied for $3 \%$ and $5 \%$ of the farms, respectively.

\section{Snail habitats}

Potential snail habitats were present in 35 out of the 39 farms. A total of 87 potential habitats were identified but intermediate host snails were only found in 25 $(29 \%)$ of them. The total number of collected snails was 432 (380 G. truncatula and 52 Radix spp.) and F. hepatica DNA was only found in $3 \%(n=13)$ of them (and only in G. truncatula).

All potential habitats were located at a distance of less than $900 \mathrm{~m}$ from a water stream: for $34 \%$ of the habitats this distance was $\leq 50 \mathrm{~m}$ and for $64 \% \leq 200 \mathrm{~m}$. Although a humid area around a water trough was also considered as a potential habitat, intermediate host snails were not found in any of them. Potential habitats were only found where the drainage classification of the soil indicated moderately humid to very wet soil (classification "c" or higher), though this variable was not available in every location. The further characterization of the potential habitats is described in Table 1. Proximity to water bodies and location in wet soils with poor drainage capacities is illustrated in Figure 1.

Factors associated with levels of exposure to $\mathrm{F}$. hepatica

The results of the multivariable regression model to evaluate associations between farm level factors with regard to management and potential habitats are displayed in Table 2. Several factors were significantly associated with the level of exposure of the farm as assessed by $F$. hepatica bulk tank ELISA and explained $85 \%$ of the observed variation. The level of exposure 
Table 1. Characterization of 87 potential habitats for the intermediate host snails of $F$. hepatica found in 39 Flemish dairy farms.

\begin{tabular}{|c|c|}
\hline Property & Number of habitats \\
\hline \multicolumn{2}{|l|}{ Surface } \\
\hline$<10 \mathrm{~m}^{2}$ & 25 \\
\hline $10-20 \mathrm{~m}^{2}$ & 38 \\
\hline$>20 \mathrm{~m}^{2}$ & 24 \\
\hline \multicolumn{2}{|l|}{ Type of pasture } \\
\hline Heifer & 52 \\
\hline Cow & 35 \\
\hline \multicolumn{2}{|l|}{ Drainage classification } \\
\hline Not defined & 17 \\
\hline Dry soils $(a, b)$ & 0 \\
\hline Moderately humid soils (c, d) & 34 \\
\hline Very humid soils (e, f, g, h, i) & 36 \\
\hline \multicolumn{2}{|l|}{ Distance to water stream } \\
\hline$\leq 50 \mathrm{~m}$ & 30 \\
\hline $51-200 \mathrm{~m}$ & 26 \\
\hline $201-900 \mathrm{~m}$ & 31 \\
\hline \multicolumn{2}{|l|}{ Type of habitat } \\
\hline Diffuse humid area & 42 \\
\hline Drainage ditch/brook & 22 \\
\hline Pool & 14 \\
\hline Water trough & 9 \\
\hline \multicolumn{2}{|l|}{ Soil type } \\
\hline Non defined & 16 \\
\hline $\operatorname{Loam}(\mathrm{A})$ & 27 \\
\hline Clay (E) & 7 \\
\hline Sandy loam $(\mathrm{L}, \mathrm{P})$ & 31 \\
\hline Heavy clay $(\mathrm{U})$ & 6 \\
\hline
\end{tabular}

increased with higher number of potential habitats and presence of snails on these habitats during the farm visit. Presence of snails was the most significant factor in predicting the level of exposure and explained by itself $24 \%$ of the observed variation. The next most significant factor was the watering place with evidence of lower levels of exposure when water was provided by a nipple or open tub instead of a pump or in the form of pool, pond or brook. Drainage of pastures, turnout after the beginning of May and stocking rate between 5 to 10 animals were also associated with lower levels of exposure. Finally, the risk area was a significant factor, suggesting that unmeasured and regionally dependent factors accounted for a significant part of the observed variation.

\section{Factors associated with presence of intermediate host} snails

As shown in Table 3, two factors indicated a significantly higher risk for the presence of G. truncatula and Radix spp. in the potential habitats: the habitat size (larger habitats meaning a higher risk for presence of snails) and the soil type (loam soils having higher risk than no-loam soils). No significant associations were found for type of pasture, presence of streaming water, distance to water, drainage classification or type of habitat.

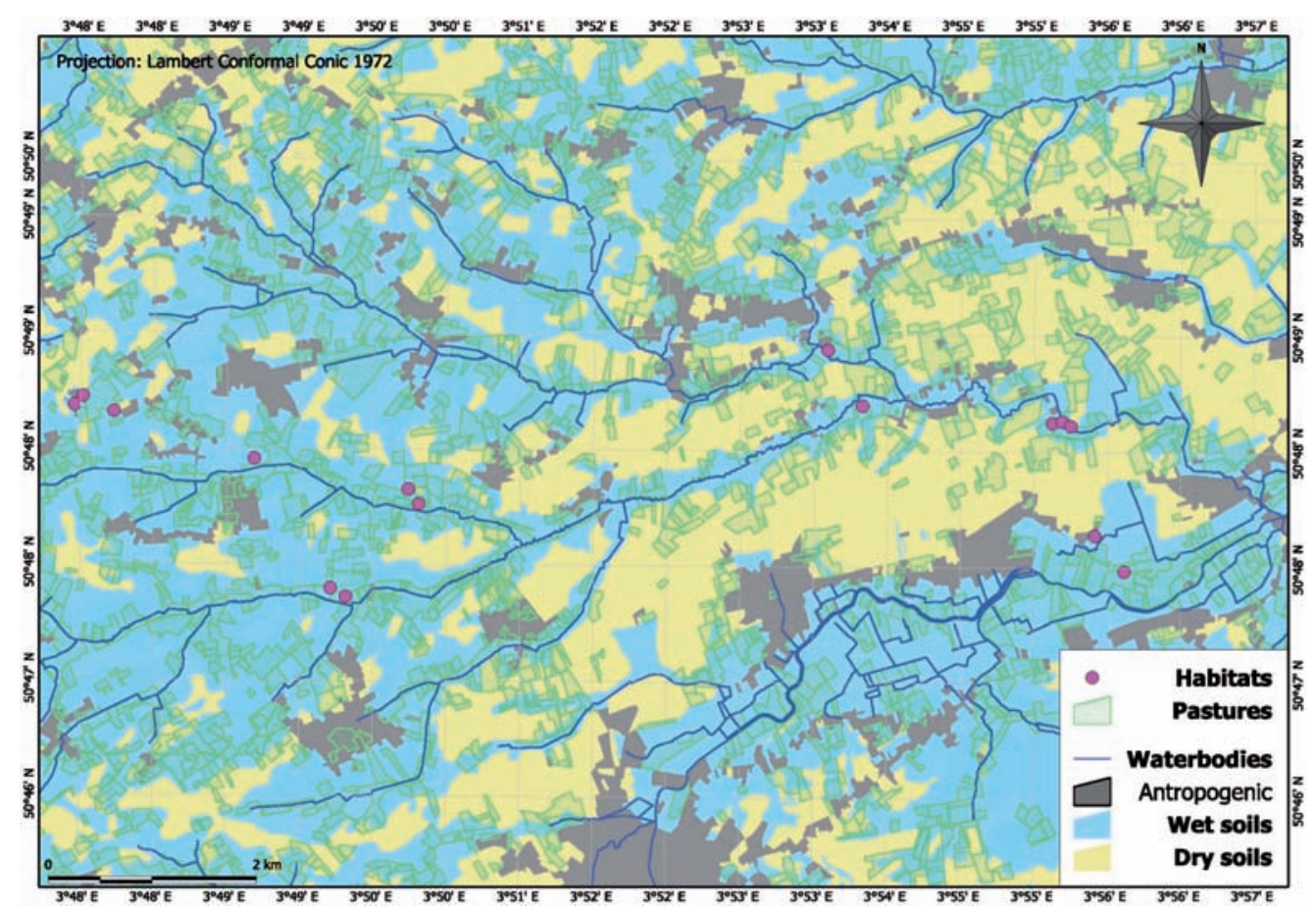

Fig. 1. Map of identified, potential habitats for G. truncatula illustrating their proximity to water bodies and preferential location in soils of poor drainage capacity. These soils, marked as blue, can be any of the humid/wet types classified by the Belgian drainage system as "c" through to "i". The soils marked as dry belong to the " $a$ " or " $b$ " classifications. 
Table 2. A multivariable regression model to evaluate associations between farm level factors concerning management and potential habitats for the intermediate host snail and F. hepatica bulk tank ELISA results $\left(N=34\right.$ dairy farms, $\left.R^{2}=0.85\right)$.

\begin{tabular}{|c|c|c|c|}
\hline Variable & B & SE & $P$ value \\
\hline Intercept & 0.772 & 0.181 & $<0.001$ \\
\hline Risk area & & & 0.033 \\
\hline High risk & - & - & \\
\hline Low risk & 0.178 & 0.078 & \\
\hline No. of potential habitats & 0.080 & 0.025 & 0.004 \\
\hline Snail presence & & & $<0.001$ \\
\hline No & - & - & \\
\hline Yes & 0.390 & 0.086 & \\
\hline Drained pastures & & & 0.023 \\
\hline Entirely & - & & \\
\hline Partly $(<80 \%)$ & 0.207 & 0.112 & \\
\hline No & 0.290 & 0.097 & \\
\hline Month of turn out & & & 0.006 \\
\hline March & - & & \\
\hline April & 0.106 & 0.183 & \\
\hline May & -0.185 & 0.193 & \\
\hline Average no. of cows on parcel per ha & & & 0.015 \\
\hline$<5$ & - & - & \\
\hline $5-10$ & -0.208 & 0.067 & \\
\hline$>10$ & 0.047 & 0.170 & \\
\hline Watering place & & & 0.030 \\
\hline Pump on pasture & - & - & \\
\hline Pool/pond/brook & 0.178 & 0.139 & \\
\hline Nipple & -0.292 & 0.124 & \\
\hline Open tub & -0.141 & 0.071 & \\
\hline
\end{tabular}

SE, standard error

\section{Discussion}

This study indicates that combined assessment of applied management and the presence of the intermediate host snail is a powerful means to predict the F. hepatica infection risk at the farm level.

The importance of management is in agreement with the results of Bennema et al. (2011), as these authors showed that management variables explained the variation in the spatial distribution of F. hepatica in dairy farms better than meteorological or environmental variables. Although most of the identified associations with factors related to management reflect common sense and are already considered risk factors for fasciolosis, few published data on this subject are available and it is only now that their impact is becoming clear.

Our results suggest that mapping potential habitats and assessing their suitability for intermediate host snails can significantly improve the accuracy and spatial resolution of distribution models for $F$. hepatica. This underlines the need for further research to investigate whether this can be achieved by high-resolution remote sensing techniques or whether physical inspection of farm premises will remain necessary (Gomez-

Table 3. A logistic mixed model to identify predictors for the presence of the intermediate host snails in 87 potential habitats in 39 Flemish dairy farms.

\begin{tabular}{|c|c|c|c|}
\hline Variable & Odds ratio & $95 \% \mathrm{CI}$ & $P$ value \\
\hline \multicolumn{4}{|l|}{ Fixed effects: } \\
\hline Surface (baseline $<10 \mathrm{~m}^{2}$ ) & & & 0.011 \\
\hline $10-20 \mathrm{~m}^{2}$ & 13.4 & $1.4-129.1$ & \\
\hline$>20 \mathrm{~m}^{2}$ & 34.1 & $3.3-357.8$ & \\
\hline Soil type (loam versus no loam) & 4.3 & $1.2-16.0$ & 0.029 \\
\hline
\end{tabular}

Random farm effect (variance $\pm \mathrm{SE}$ )

$0.869 \pm 0.805$

CI, confidence interval; SE, standard error 
Rodriguez et al., 2008). Further characterization of the habitats and of the factors that determine their suitability for the intermediate host snails (Schweizer et al., 2007; Rondelaud et al., 2009; Relf et al., 2011) are indispensable in this respect. The absence of any potential habitats in soils classified as "dry" (score a or b), or around water troughs and their location in parallel with water streams, was in our opinion remarkable (Fig. 1). However, the small scale of the survey and the fact that our observations were based on a single farm visit preclude any firm conclusions to be drawn.

This survey focused on F. hepatica transmission risk in cattle and infection of humans with this parasite is extremely rare in Belgium. Nonetheless, insights from this study could be used to improve mapping of F. hepatica in humans in endemic regions because cattle likely play a major role in the transmission risk to humans (Fuentes, 2006; Nguyen et al., 2010).

The prevalence of $F$. hepatica in the retrieved snails (3\%) was lower than the $7 \%$ recently reported from Switzerland where a PCR assay was used (Schweizer et al., 2007) and particularly the high level (27\%) from the Poland (Kozak and Wedrychowicz, 2010). This may be due to the period of sampling in our study, which was later in the year than the study of Kozak and Wedychowicz (2010) and may be considered suboptimal for retrieval of infected snails. However, although the monitoring of snail infection can be a valuable tool for epidemiological studies (Kozak and Wedrychowicz, 2010), our results suggest that, in Belgium, it is not necessary to assess the risk of infection of the animals: once the intermediate host has been found and is combined with a type of management that favours transmission, the risk for infection of the animals is obvious, irrespective whether $F$. bepatica infection of the snail can be demonstrated or not.

\section{Acknowledgements}

The authors would like to thank all 39 farmers for their participation in this survey. This work was supported by the agency for Innovation by Science and Technology of Flanders (IWT) (project no. OZM090697).

\section{References}

Bennema S, Vercruysse J, Claerebout E, Schnieder T, Strube C, Ducheyne E, Hendrickx G, Charlier J, 2009. The use of bulktank milk ELISAs to study the spatial distribution of Fasciola hepatica, Ostertagia ostertagi and Dictyocaulus viviparus in Flanders (Belgium). Vet Parasitol 165, 51-57.

Bennema SC, Ducheyne E, Vercruysse J, Hendrickx G, Claerebout E, Charlier J, 2011. Relative importance of management, meteorological and environmental factors in the spatial distribution of Fasciola hepatica in dairy cattle in a temperate climate zone. Int J Parasitol 41, 225-233.

Caron Y, Lasri S, Losson B, 2007. Fasciola hepatica: an assessment on the vectorial capacity of Radix labiata and R. balthica commonly found in Belgium. Vet Parasitol 149, 95-103.

Charlier J, Duchateau L, Claerebout E, Williams D, Vercruysse J, 2007. Associations between anti-Fasciola hepatica antibody levels in bulk-tank milk samples and production parameters in dairy herds. Prev Vet Med 78, 57-66.

Charlier J, Sanders M, Vercruysse J, 2009. The direct costs of infections with gastrointestinal nematodes and liver fluke in the Flemish dairy population. Vlaams Diergen Tijds 78, 196-200.

Cringoli G, Rinaldi L, Veneziano V, Capelli G, Malone JB, 2002. A cross-sectional coprological survey of liver flukes in cattle and sheep from an area of the southern Italian Apennines. Vet Parasitol 108, 137-143.

Durr PA, Tait N, Lawson AB, 2005. Bayesian hierarchical modelling to enhance the epidemiological value of abattoir surveys for bovine fasciolosis. Prev Vet Med 71, 157-172.

Dutra LH, Molento MB, Naumann CRC, Biondo AW, Fortes FS, Savio D, Malone JB, 2010. Mapping risk of bovine fasciolosis in the south of Brazil using geographic information systems. Vet Parasitol 169, 76-81.

Frömming E, 1956. Biologie der mitteleuropäischen Süsswasserschnecken, Duncker \& Humblot, Berlin, Germany, 313 pp.

Fuentes MV, 2006. Remote sensing and climate data as a key for understanding fasciolosis transmission in the Andes: review and update of an ongoing interdisciplinary project. Geospat Health 1, 59-70.

Gomez-Rodriguez G, Bustamante J, Koponen S, Diaz-Paniagua C, 2008. High-resolution remote-sensing data in amphibian studies: identification of breeding sites and contribution to habitat models. Herpetol J 18, 103-113.

Kaplan RM, Dame JB, Reddy GR, Courtney CH, 1995. A repetitive DNA probe for the sensitive detection of Fasciola hepatica infected snails. Int J Parasitol 25, 601-610.

Kozak M, Wedrychowicz H, 2010. The performance of a PCR assay for field studies on the prevalence of Fasciola hepatica infection in Galba truncatula intermediate host snails. Vet Parasitol 168, 25-30.

Malone JB, Zukowski SH, 1992. Geographic models and control of cattle liver flukes in the southern USA. Parasitol Today 8, 266-270.

McCann CM, Baylis M, Williams DJL, 2010. The development of linear regression models using environmental variables to explain the spatial distribution of Fasciola hepatica infection 
in dairy herds in England and Wales. Int J Parasitol 40, 10211028.

Nguyen TG, Le TH, Dao TH, Tran TL, Praet N, Speybrouck N, Vercruysse J, Dorny P, 2011. Bovine fasciolosis in the human fasciolosis hyperendemic Binh Dinh province in central Vietnam. Acta Trop 117, 19-22.

Nisters H, 1999. Freshwater shells. Visited on: http://www.microscopy-uk.org.uk/mag/indexmag.html? http://www.microscopyuk.org.uk/mag/artsep99/hnshell3.html (accessed on October 2008)

Rapsch C, Dahinden T, Heinzmann D, Torgerson PR, Braun U, Deplazes P, Hurni L, Bar H, Knubben-Schweizer G, 2008. An interactive map to assess the potential spread of Lymnaea truncatula and the free-living stages of Fasciola hepatica in Switzerland. Vet Parasitol 154, 242-249.

Relf V, Good B, Hanrahan JP, McCarthy E, Forbes AB, deWaal T, 2011. Temporal studies on Fasciola hepatica in Galba truncatula in the west of Ireland. Vet Parasitol 175, 287-292.

Relf V, Good B, McCarthy E, de Waal T, 2009. Evidence of Fasciola hepatica infection in Radix peregra and a mollusc of the family of Succineidae in Ireland. Vet Parasitol 163, 152-155.

Rondelaud D, Hourdin P, Vignoles P, Dreyfuss G, 2009. Galba truncatula (Gastropoda, Lymnaeidae): first findings on populations showing a single annual generation in lowland zones of central France. Ann Limnol - Int J Lim 45, 51-54.

Schweizer G, Meli ML, Torgerson PR, Lutz H, Deplazes P, Braun U, 2007. Prevalence of Fasciola hepatica in the intermediate host Lymnaea truncatula detected by real time TaqMan PCR in populations from 70 Swiss farms with cattle husbandry. Vet Parasitol 150, 164-169.

Tum S, Puotinen ML, Copeman DB, 2004. A geographic information systems model for mapping risk of fasciolosis in cattle and buffaloes in Cambodia. Vet Parasitol 122, 141-149.

Van Ranst E, Sys C, 2000. Eénduidige legende voor de digitale bodemkaart van Vlaanderen (schaal 1:20 000). Laboratorium voor Bodemkunde, Ghent University, Belgium, 361 pp.

Yilma JM, Malone JB, 1998. A geographic information system forecast model for strategic control of fasciolosis in Ethiopia. Vet Parasitol 78, 103-127.

Zukowski SH, Hill JM, Jones FW, Malone JB, 1991. Development and validation of a soil-based geographic information-system model of habitat of Fossaria bulimoides, a snail intermediate host of Fasciola hepatica. Prev Vet Med 11, 221-227.

Zukowksi SH, Wilkerson GW, Malone JB, 1993. Fasciolosis in cattle in Louisiana. II. Development of a system to use soil maps in a geographic information system to estimate disease risk on Louisiana coastal marsh rangeland. Vet Parasitol 47, 51-65. 